\title{
Um olhar sobre os rostos da Palestina: notas introdutórias à filosofia política de Judith Butler
}

\author{
A look at the faces of Palestine: introductory notes to Judith \\ Butler's political philosophy
}

Una mirada sobre los rostros de Palestina: notas introductorias a la filosofía política de Judith Butler

\begin{abstract}
Almerindo A. Boff ${ }^{\prime}$
Universidade de Santa Cruz do Sul, Santa Cruz do Sul, RS, Brasil.
\end{abstract}

\section{Resumo}

Judith Butler tornou-se reconhecida inicialmente por seu posicionamento no campo dos estudos do gênero. Nas últimas décadas, sua obra passou a abordar consistentemente temas da filosofia política, incluindo as suas perspectivas teóricas do movimento sionista e do Estado de Israel contemporâneos, feitas na companhia das reflexões de Walter Benjamin, Hanna Arendt e Emmanuel Lévinas, entre outros. O presente artigo enfoca inicialmente, de maneira sintética, algumas destas reflexões, examinando aproximações entre os pensamentos de Butler e Lévinas. Essas reflexões são a seguir tomadas para enfatizar aspectos importantes para a compreensão do seu pensamento quanto aos temas da ontologia, da relação entre ética e constituição do sujeito, e das relações entre pluralidade, performatividade, multiculturalismo e ativismo social.

Palavras-chave: Butler. Lévinas. Palestina. Ontologia. Ativismo social.

\footnotetext{
Doutor em Filosofia pela Pontifícia Universidade Católica do Rio Grande do Sul (PUCRS). Membro Pleno da Sigmund Freud Associação Psicanalítica (Porto Alegre/RS). Professor adjunto da Universidade de Santa Cruz do Sul (UNISC/RS).http://orcid.org/0000-0002-7034-3805. E-mail:abcdboff@gmail.com
} 


\begin{abstract}
Judith Butler was initially recognized for her positioning in the field of gender studies. In the last decades her work has consistently addressed themes of political philosophy, including her theoretical perspectives on contemporary Zionist movement and the State of Israel, made in the company of the reflections of Walter Benjamin, Hanna Arendt and Emmanuel Lévinas, among others. This article initially summarizes some of these reflections, and then uses them to address approximations from the thinking of Butler and Lévinas. These reflections are then taken to highlight important aspects of her thinking in the realms of ontology, of the relationships between ethics and the constitution of the subject, and of the relationships between plurality, performativity, multiculturalism and social activism.
\end{abstract}

Keywords: Butler. Lévinas. Palestine. Ontology. Social activism.

\title{
Resumen
}

Judith Butler se reconoció inicialmente por su posición en el campo de las teorías del género. En las últimas décadas su obra pasó a abordar consecuentemente temas de la filosofía política, incluyendo sus perspectivas teóricas del movimiento sionista y del Estado de Israel contemporáneos, hechas en compañía de las reflexiones de Walter Benjamin, Hanna Arendt y Emmanuel Lévinas, entre otros. Este artículo presenta inicialmente, de manera sintética, algunas de estas reflexiones, para luego tomarlas para hacer enfoques entre los pensamientos de Butler y Lévinas. Ellas son tomadas también para relacionarlas con aspectos importantes de su pensamiento en cuanto a los temas de la ontología, de la relación entre ética y constitución del sujeto, y de las relaciones entre pluralidad, performatividad, multiculturalismo y activismo social.

Palabras clave: Butler. Lévinas. Palestina. Ontología. Activismo social.

\section{Introdução}

Judith Butler tornou-se reconhecida inicialmente por seu posicionamento no campo das teorias do gênero, passando progressivamente a assumir maior relevo em sua produção textual alguns temas no campo da filosofia política. Isso a conduziu a uma retomada do exame de conceitos já desenvolvidos por ela, agora nesse contexto específico. O presente trabalho visa levar ao leitor uma perspectiva de seus desenvolvimentos 
teóricos nas últimas décadas a partir da articulação de sua crítica ao movimento sionista e ao Estado de Israel contemporâneos com alguns conceitos que ela trabalha ao longo de sua obra e que aqui destacamos. Enfocaremos, a partir de seus posicionamentos em relação a esse tema específico, as suas reflexões acerca de temas da ontologia, da ética e da constituição do sujeito no âmbito do seu diálogo com textos de Emmanuel Lévinas. Essas, por sua vez, são articuladas por ela com temas presentes desde as suas obras iniciais, como os temas da pluralidade em sua relação com o multiculturalismo, e da performatividade em sua relação com o ativismo social. Com esse itinerário em mente, iniciaremos realizando uma breve apresentação do percurso intelectual da autora.

\section{Judith Butler}

Nascida nos Estados Unidos em 1956, descende de pais judeus nascidos na Hungria e na Rússia, tendo a maior parte da família da sua avó materna perecido no Holocausto. Como criança e adolescente frequentou escola judaica e classes especiais de ética judaica onde, aos 14 anos, preocupava-se com três questões: "Por que Spinoza foi excomungado da sinagoga? Poderia o Idealismo Alemão ser considerado responsável pelo Nazismo? E como se deveria entender a teologia existencial, incluindo o trabalho de Martin Buber"?²

Estudou filosofia na Yale University, onde obteve o grau de Doutor em filosofia em 1984 com tese sobre a recepção de Hegel na França no século XX, revisada e publicada em 1987. Parte do exame dos temas do desejo e do reconhecimento na "Fenomenologia do espírito". Aborda a seguir as recepções de Hegel em Kojève, Hyppolite e Sartre, para depois

\footnotetext{
2 BUTLER, Judith. A conversation at Wesleyan University's Center for Humanities. [Entrevista cedida a Michael Roth em 13 de fevereiro de 2013] Disponível em: https://www.youtube.com/ watch?V=Rf4px4KyqbY Acesso em: 2 out. 2019. A citação está referida na seção "Early life and education" da página "Judith Butler" na Wikipedia, que também disponibiliza o link para o vídeo da entrevista. Disponível em: https://en.wikipedia.org/wiki/Judith_Butler. Acesso em: 2 out. 2019.
} 
enfocá-la nas obras de Lacan, Derrida, Deleuze e Foucault³ ${ }^{3}$ Sua formação acadêmica focou primariamente o Idealismo Alemão, a fenomenologia e o trabalho da Escola de Frankfurt, voltando em seguida sua atenção para o pós-estruturalismo francês. ${ }^{4}$

No ano seguinte, em 1988, passa a problematizar o tema da performatividade do gênero no ensaio "Performative acts and gender constitution: an essay in phenomenology and feminist theory"5. Torna-se amplamente conhecida com a publicação, em 1990, de Problemas de gênero: feminismo e subversão da identidade, onde segue trabalhando

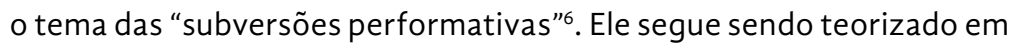
Bodies that matter: on the discursive limits of 'sex", em Excitable speech: a politics of the performative ${ }^{8}$, e em Undoing gender .

Já amplamente conhecida por sua produção intelectual no campo dos estudos de gênero, a importância do seu trabalho filosófico é também reconhecida, como atesta a sua nomeação para a Spinoza Chair na Universidade de Amsterdam em 2002. Na virada do século, no ano 2000, ela se encontra envolvida na discussão do tema da performatividade em conexão com os temas, por nós aqui selecionados, da ontologia, das implicações éticas das teorias da constituição do sujeito e das implicações

3 BUTLER, Judith. Subjects of desire: hegelian reflections in twentieth century France. New York: Columbia University Press, 1987.

4 Judith Butler ocupa a Hanna Arendt Chair na The European Graduate School, que apresenta em seu site uma interessante biografia da autora. Disponível em: https://www.egs.edu/faculty/ judith-butler. Acesso em: 19 jun. 2019.

5 BUTLER, Judith. Performative acts and gender constitution: an essay in phenomenology and feminist theory. Theatre Journal. The Johns Hopkins University Press, v. 40, n. 4, p. 519531. Dec., 1988.

6 BUTLER, Judith. Problemas de gênero: feminismo e subversão da identidade. 17. ed. Tradução: Renato Aguiar. Rio de Janeiro: Civilização Brasileira, 2019.

7 BUTLER, Judith. Bodies that matter: on the discursive limits of "sex". London: Routledge, 1993.

8 BUTLER, Judith. Excitable speech: a politics of the performative. London and New York: Routledge, 1997.

9 BUTLER, Judith. Undoing gender. London: Routledge, 2004. 
da teoria psicanalítica para uma teoria da política..$^{0}$ Em Undoing gender, recém referido, o diálogo com Hegel e Spinoza é retomado quanto às questões do desejo e do reconhecimento, em especial, no que se refere à estrutura diádica do reconhecimento hegeliano. Partem de Hegel os temas que vão se tornando progressivamente mais importantes em seus trabalhos, como a relacionalidade, a ek-stasis e a despossessãon".

Ainda em 2004, publica Precarious life: the powers of mourning and violence $^{12}$, agora já abordando extensamente o tema dos riscos da crítica ao sionismo e à política do Estado de Israel contemporâneo. Nessa obra ela aprofunda também os temas da vulnerabilidade e da precariedade da vida, afirmando que a vida é essencialmente precária e vulnerável.

Em 2005, ela abordará em livro'3 o problema filosófico da violência ética, em diálogo com Hegel, Kafka, Adorno, Lévinas e Foucault, entre outros. O diálogo com Hegel, Walter Benjamin e Lévinas é retomado em 2009 em Quadros de guerra: quando a vida é passível de luto? ${ }^{\text {14, }}$ onde ela revisita os temas da precariedade e da vulnerabilidade em relação com o multiculturalismo.

Em 2013 ela enfocará os temas da despossessão em sua relação com a performatividade no político ${ }^{15}$, voltando a abordar amplamente esse tema em 2015 na obra Corpos em aliança e a política das ruas: notas para uma teoria performativa da assembleia. Aqui ela oferece uma nova perspectiva ao seu conceito de performatividade, pelo qual o corpo

\footnotetext{
10 BUTLER, Judith; LACLAU, Ernesto; ZIZEK, Slavoy. Contingency, hegemony, universality: contemporary dialogues on the left. London: Verso, 2000.

1 O percurso de Butler no estudo destes três temas é examinado em obra recente: SCHIPPERS, Birgit. The political philosophy of Judith Butler. London and New York: Routledge, 2014.

12 BUTLER, Judith. Precarious life: the powers of mourning and violence Undoing gender. London and New York: Routledge, 2004.

13 BUTLER, Judith. Relatar a si mesmo: crítica da violência ética. Tradução: Rogério Bettoni. Belo Horizonte: Autêntica Editora, 2017.

14 BUTLER, Judith. Quadros de guerra: quando a vida é passível de luto? 5. ed. Tradução: Sérgio Lamarão e Arnaldo Marques da Cunha. Rio de Janeiro: Civilização Brasileira, 2018.

15 BUTLER, Judith; ATHANASIOU, Athena. Dispossession: the performative in the political. Cambridge (UK): Polity Press, 2013.
} 
individual, em aliança com outros corpos, pode estabelecer performativamente um campo do político e apoiar uma ação concertada. Nessa, o aparecimento do corpo evidencia a sua precariedade, mas também a sua resistência e persistência ${ }^{16}$. Suas contribuições recentes mostram um aprofundamento do trabalho de construção de pontes teóricos entre os campos fronteiriços da psicanálise, da psicologia, da filosofia moral, da teoria social e da filosofia política ${ }^{17}$.

Sua crítica ao movimento sionista e à política do Estado de Israel contemporâneos é aprofundada em sua publicação "Caminhos divergentes: judaicidade e crítica do sionismo", em $2012^{18}$, onde ela dialoga com o pensamento filosófico de Walter Benjamin, Hanna Arendt e Emmanuel Lévinas, entre outros. Passaremos a examinar este aspecto do seu trabalho na seção a seguir.

16 BUTLER, Judith. Corpos em aliança e a política das ruas: notas para uma teoria performativa da assembleia. 2. ed. Tradução: Fernanda Siqueira Miguens. Rio de Janeiro: Civilização Brasileira, 2018.

17 Apresento algumas sugestões para o leitor interessado neste desenvolvimento do seu pensamento: BUTLER, Judith. Rethinking vulnerability and resistance. In: BUTLER, Judith; GAMBETTI, Zeynep; SABSAY, Leticia (ed.) Vulnerability in resistance. London: Duke University Press, 2016; BUTLER, Judith. Levantes. In: DIDI-HUBERMAN, Georges (org.). Levantes. Tradução: Jorge Bastos, Edgard de Assis Carvalho, Mariza Perassi Bosco e Eric R. R. Heneault. São Paulo: Edições SESC São Paulo, 2017. Debates interessantes com Judith Butler se encontram em GIULIANI, Facundo (org.) Rebeliones éticas, palabras comunes: conversaciones (filosóficas, políticas, educativas) com Judith Butler, Raúl Fornet-Betancourt, Walter Mignolo, Jacques Rancière e Slavoy Zizek. Buenos Aires: Mino y Dávila Editores, 2017. Uma discussão interessante e atual sobre as relações entre filosofia e ativismo está na entrevista que ela concede ao Dorsal Journal, publicada em 2018 (Dorsal. Revista de Estudios Foucaultianos, n. 1, p. 111-117, junio, 2018,. Disponível em: http:// www.revistas.cenaltes.cl/index.php/dorsal Acesso em: 21 jun. 2019. Recomendo também duas conferências que ela proferiu como Tanner Lectures em Yale em 2016, e que estão disponíveis no YouTube: “Why preserve the life of the Other?" e "Legal violence: on ethical and political critique". As conferências são seguidas de um debate no mesmo evento, também disponível no YouTube.

18 BUTLER, Judith. Caminhos divergentes: judaicidade e crítica do sionismo. 5. ed. Tradução: Rogério Bettoni. São Paulo: Boitempo, 2017. O título da posterior publicação em francês enfatiza um dos temas problematizados no livro que é o tema da coabitação: BUTLER, Judith. Vers la cohabitation: judéité et critique du sionisme. Paris: Fayard, 2013. 


\section{Crítica ao sionismo e ao Estado de Israel contemporâneos}

Um número recorde de 70,8 milhões de pessoas fugia de situações de guerra, perseguição e conflito em 2018, afirmou o Alto-Comissariado da ONU para os refugiados (ACNUR) em seu relatório anual, divulgado em 19 de junho de 2019. Desses, 5,5 milhões são palestinos, que estão sob responsabilidade de uma agência específica da ONU.

A questão dos refugiados palestinos vem sendo objeto da reflexão filosófica de Butler neste início de século. Ela é membro do Board of Directors da FFIPP - USA - Educational Network for Human Rights in Israel/Palestine ${ }^{19}$, e membro do Advisory Board do Jewish voice for peace $^{20}$. Quando recebeu o Prêmio Adorno, em 2012, o comitê que a indicou foi atacado por essa indicação pelo Embaixador de Israel, pelo Diretor do escritório do Simon Wiesenthal Center em Jerusalém e pelo German Central Council for Jews, que consideravam suas posições como estímulo a um "boicote contra Israel". Em resposta, ela afirmou que esses ataques são dirigidos contra qualquer um que seja crítico contra o Estado de Israel e suas políticas atuais ${ }^{21}$.

Suas críticas ao movimento sionista e ao Estado de Israel contemporâneos são aprofundadas na recém citada obra Caminhos divergentes: judaicidade e crítica do sionismo, publicada em 2012, e retomadas também em 2015 em Corpos em aliança e a política das ruas: notas para uma teoria performativa da assembleia. ${ }^{22}$

Podemos ilustrar sinteticamente a situação vivida atualmente pelos palestinos lembrando que 5,5 milhões deles são reconhecidos pela ONU como refugiados. Segundo Butler, os que vivem na Palestina habitam locais

\footnotetext{
19 Disponível em: http://ffipp.org/us/. Acesso em: 20 jun. 2019.

20 Ver https://jewishvoiceforpeace.org. Acesso em: 20 jun. 2019.

${ }_{21}$ Ver https://en.wikipedia.org/wiki/Judith Butler. Acesso em: 20 jun. 2019.

22 BUTLER, Judith. Corpos em aliança e a política das ruas: notas para uma teoria performativa da assembleia. 2. ed. Tradução: Fernanda Siqueira Miguens. Rio de Janeiro: Civilização Brasileira, 2018.
} 
onde "as condições infraestruturais de vida são constantemente destruídas pelos bombardeios, pelo racionamento de água, pela destruição dos olivais e pelo desmantelamento dos sistemas de irrigação construídos". ${ }^{23}$ Mikko Joronen apresenta um exame recente da situação política de precarização da vida na Palestina utilizando aspectos da filosofia política de Butler. ${ }^{24}$

Para as finalidades das presentes notas introdutórias ao pensamento filosófico da autora, apresentarei inicialmente breves recortes da já citada obra Caminhos divergentes. Ela partiu da crítica à ideia de que toda crítica ao Estado de Israel contemporâneo é prática antissemita para buscar desenvolver uma crítica judaica da violência exercida por ele nas práticas de subjugação colonial, expulsão e despossessão de populações palestinas. Para isso, examina momentos do pensamento sionista do início do século XX em cotejo com as políticas atuais do Estado de Israel. Entre os autores com quem ela dialoga na sua busca por esta crítica judaica, salientamos aqui Franz Rosenzweig, Martin Buber, Walter Benjamin, Hanna Arendt e Emmanuel Lévinas. No presente artigo nos limitaremos a apresentar alguns momentos do seu diálogo com Lévinas.

No que se refere a esse último, é muito importante enfatizar que as passagens aqui selecionadas não são aquelas em que Butler concorda com Lévinas e que constituem as partes mais conhecida do pensamento do autor. Ao invés disto, iremos salientar aqui suas passagens talvez menos conhecidas e que a levam a dizer:

$\mathrm{Na}$ verdade, inicialmente eu esperava conseguir extrair de Lévinas a mais forte declaração judaica de uma obrigação ética para com o outro, uma vez que tal obrigação não seria contingente, mas resultaria da constituição da subjetividade

\footnotetext{
23 Idem, p. 19.

24 JORONEN, Mikko. Negotiating colonial violence: spaces of precarisation in Palestine. Antipode. v. 51, n. 3, p. 838-857, 2019. São também importantes para a discussão dos conflitos na Palestina as contribuições de llan Pappé, entre elas: PAPPÉ, llan. The ethnic cleansing of Palestine. London: Oneworld Publications, 2006; CHOMSKY, Noam; PAPPÉ, Ilan. On Palestine. Chicago: Haymarket Books, 2015.
} 
pela alteridade e na alteridade. É claro, fazer uso de Lévinas para uma política de esquerda é justamente interpretá-lo contra seu próprio sionismo e sua recusa de aceitar que os palestinos tenham uma exigência ética legítima em relação ao povo judeu. Em termos filosóficos, Lévinas esboça uma cena ética na qual somos obrigados, na maioria das situações, a preservar a vida do outro - obrigados pela alteridade que ali encontramos. Sob uma análise mais detalhada, no entanto, descobre-se que essa cena, que parecia nos obrigar universalmente, é restrita em termos culturais e geográficos. A obrigação ética para com o rosto do outro não é uma obrigação que alguém pode ou consegue sentir em relação a todo e qualquer rosto. ${ }^{25}$

O livro Caminhos divergentes apresenta extenso diálogo de Butler com textos de Lévinas. Em vista das limitações de espaço do presente artigo, apresentarei apenas algumas passagens dentre as que ela apresenta em sustentação a esta ideia. Ela parte da aceitação de Lévinas quanto a que o contato com a alteridade pela interpelação pelo "rosto" dá vida à cena ética, constituindo um momento interpretativo que não depende de nenhum precedente histórico ou textual. O "rosto" não é necessariamente o rosto literal, consistindo em uma injunção à não violência conduzida por vários sentidos, sendo que qualquer sinal de susceptibilidade conta como o "rosto". ${ }^{26}$

É amplamente conhecida a coerência do pensamento do autor em torno desta sua concepção da ética como filosofia primeira. O que Butler irá salientar, no entanto, são algumas passagens de Lévinas que ela interpreta como uma vacilação do filósofo em estender incondicionalmente

\footnotetext{
25 BUTLER, Judith. Caminhos divergentes: judaicidade e crítica do sionismo. 5. ed. Tradução: Rogério Bettoni. São Paulo: Boitempo, 2017. p. 47.

26 Idem, p. 19-21.
} 
a exigência ética frente ao rosto a todos os seres humanos em todas as situações. Vamos citar aqui dois exemplos.

A violência dos exércitos usada na defesa do Estado de Israel deve deter-se frente ao rosto dos palestinos? Os palestinos assassinados para a defesa de Israel não têm rosto? O assunto é trazido por ela a partir de uma entrevista com Lévinas realizada após os acontecimentos que se seguiram ao atentado à bomba ocorrido em Beirute em 14 de setembro de 1982 em que morreram o Presidente do Líbano e outras vinte e seis pessoas. No dia seguinte Israel ocupou Beirute Ocidental alegadamente em defesa da segurança, ato ao qual se seguiram ações violentas protagonizadas pelas Forças de Defesa de Israel na qual centenas de pessoas foram massacradas nos campos palestinos de Sabra e Chatila. Nesta entrevista com Lévinas, realizada em 28 de setembro de 1982, ele aborda a questão da contradição direta entre ética e política, salientando a necessidade ética da ação do exército de Israel em defesa do povo judeu, sendo então indagado por Schlomo Malka: “[...] não é a política o próprio lugar do encontro com o 'outro', e para os israelitas, não é o "outro" acima de tudo os palestinos"? ${ }^{27}$ As manifestações de Lévinas nessa entrevista, entre outras, levam Butler a sugerir o estudo dos "sem-rosto" em Lévinas, podendo os palestinos serem pensados como "um paradigma para os sem rosto", sendo a proibição da violência restrita a pessoas cujos rostos são diferenciados em virtude de fundamentos religiosos e culturais ${ }^{28}$.

O exemplo acima, bem como o que se segue, estão referidos em "Caminhos divergentes". ${ }^{29}$ Neste próximo exemplo, ela se refere a uma passagem de Lévinas em que ele se refere a "massas de asiáticos e povos subdesenvolvidos" como "pessoas e civilizações" que ameaçam a "recém-fundada autenticidade" daqueles povos que compartilham "nossa

\footnotetext{
27 HAND, Seán. (ed.) The Levinas reader. Oxford: Blackwell Publishing, 1989. pp. 292-4.

${ }_{28}$ BUTLER, Judith. Caminhos divergentes: judaicidade e crítica do sionismo. 5. ed. Tradução: Rogério Bettoni. São Paulo: Boitempo, 2017. p. 47.

29 Idem, p. 32.
} 
História Sagrada”, povos estes para quem "Abraão, Isaac e Jacó não mais significam qualquer coisa" ${ }^{30}$

Para ela, os palestinos e "as massas de asiáticos e povos subdesenvolvidos" aparecem nessas passagens como imagens do sem-rosto que entram em contradição com a própria prescrição levinasiana de extrapolação política da proibição de matar ${ }^{31}$. A implantação do Estado de Israel na Palestina, com o deslocamento forçado em massa de mais de 750 mil palestinos de suas casas e vilarejos só em 1948, até a situação atual de 5,5 milhões de refugiados palestinos e das condições de vida precária em que vivem os palestinos não deslocados, evidenciam a contradição estabelecida entre a política de ocupação colonial da Palestina por Israel e a defesa da universalização de uma ética judaica na qual o judaísmo e o cristianismo seriam as precondições culturais e religiosas da própria racionalidade ética. ${ }^{32}$

Estas breves citações têm por objetivo ilustrar a posição de Butler em defesa de uma ética radical que atende à interpelação pelo rosto em todas as suas manifestações, incluindo tanto o inimigo humano quanto todos os seres não humanos com quem coabitamos no planeta Terra. Esta ideia pode estar sintetizada nesta frase:

Uma coisa é se sentir vivo ou afirmar a condição de estar vivo, e outra é dizer que esse sentido fugaz é tudo que podemos esperar da política. Sentir-se vivo não é exatamente o mesmo que lutar por um mundo no qual a vida se torne possível de ser vivida para aqueles que ainda não foram valorados como seres vivos ${ }^{33}$.

\footnotetext{
30 LÉVINAS, Emmanuel. Difficult freedom: essays on judaism. Baltimore: The Johns Hopkins University Press, 1997. pp. 164-5.

${ }_{31}$ BUTLER, Judith. Caminhos divergentes: judaicidade e crítica do sionismo. 5. ed. Tradução: Rogério Bettoni. São Paulo: Boitempo, 2017. p. 47.

32 Idem, p. 53.

33 BUTLER, Judith. Corpos em aliança e a política das ruas: notas para uma teoria performativa da assembleia. 2. ed. Tradução: Fernanda Siqueira Miguens. Rio de Janeiro: Civilização Brasileira, 2018. p. 200.
} 
A referência à contradição nestas passagens de Lévinas enfatiza também a adesão de Butler à ideia da divisão do sujeito, sempre assombrado por um Outro que impede a síntese totalmente coerente do si-mesmo, como se evidencia na seguinte passagem:

O relato que faço de mim mesma é parcial, assombrado por algo para o qual não posso conceber uma história definitiva. Não posso explicar exatamente por que surgi dessa maneira, e meus esforços de reconstrução narrativa são sempre submetidos à revisão. Há algo em mim e de mim do qual não posso dar um relato ${ }^{34}$.

Retomaremos o tema da relação entre ética e constituição do sujeito em seção adiante. Nas seções a seguir tomaremos os temas até aqui apresentados para esclarecer algumas posições teóricas de Butler que perpassam e sustentam o desenvolvimento do seu pensamento.

\section{Ontologia}

Recordemos inicialmente que a tese de doutoramento de Butler ${ }^{35}$, apresentada em 1984, parte do exame da questão do desejo e do reconhecimento na "Fenomenologia do espírito", sendo uma das seções introdutórias da tese dedicada ao exame da ontologia do desejo em Hegel. Ele permanecerá constante interlocutor de Butler. Três pontos na linha do tempo podem ilustrar brevemente esta afirmação: é o escolhido para sua tese de doutoramento no início dos anos 80; na primeira década do século XXI debate com Catherine Malabou sobre a relação do corpo com

\footnotetext{
34 BUTLER, Judith. Relatar a si mesmo: crítica da violência ética. Tradução: Rogério Bettoni. Belo Horizonte: Autêntica Editora, 2017. p. 55.

35 BUTLER, Judith. Subjects of desire: hegelian reflections in twentieth century France. New York: Columbia University Press, 1987.
} 
a dominação e a servidão em Hegel $^{36}$; em publicação de janeiro de 2018 dialoga com Hegel na sua resposta às críticas e comentários ao seu livro "Senses of the subject"37:

[...] qualquer tentativa de definir o humano sem recurso à vida da criatura fracassa precisamente porque a relação é constitutiva (razão pela qual o humano é uma criatura humana). No ato de reconhecimento mútuo tão central à "Fenomenologia do Espírito", o outro de início parece ser estruturalmente e substancialmente como eu, não posso encontrar diferenciação e sofrer o colapso dos dois polos. [...the other at first seems to be structurally and substantially the same as myself, and so I can find no difference, no differentiation, and suffer that collapse of the two poles.] Minha única opção é destruir o outro a fim de torná-lo determinado e diferenciado para mim. E então, como resultado de compreender o outro como vivo e destrutível como eu, venho a compreender a diferença entre aquela outra vida e a minha própria. Venho também a aprender algo a respeito da reciprocidade. $O$ que eu considero fazer para o outro pode ser feito para mim, e isso significa que o meu ato nunca é meu ato somente, mas potencialmente qualquer número de atos, e que eu posso estar em qualquer dos lados do ato destrutivo; como resultado, já estamos ligados pela ação - ou pela ação imaginada - por um laço de reciprocidade que eu só posso negar às custas da própria vida. Este caráter de laço da socialidade é parte do que eu compreendo como 'Espírito' em Hegel [...].38

Tomo essa citação para introduzir o modo como ela constrói a ligação entre ontologia, ética e política. Inicialmente enfatizaremos a ligação

\footnotetext{
${ }^{36}$ BUTLER, Judith; MALABOU, Catherine. Sois mon corps: une lecture contemporaine de la domination et de la servitude chez Hegel. Montrouge (FR): Bayard Éditions, 2010.

37 BUTLER, Judith. Senses of the subject. New York: Fordham University Press, 2015.

${ }_{38}$ BUTLER, Judith. Reply from Judith Butler. Philosophy and Phenomenological Research. v. XCVI, n. 1, jan. 2018. p. 249. (Tradução livre do presente autor).
} 
que ela estabelece entre ontologia e ética, a qual leva Ann V. Murphy a falar de sua "ontologia ética", que recusa a prioridade de qualquer das duas sobre a outra. Inspirada em Lévinas, entre outros, trata-se de uma concepção da ontologia que privilegia figuras como exposição à violência, despossessão, vulnerabilidade e condição precária (precariousness) ${ }^{39}$. Um corpo humano é por definição vulnerável, e o "fato ontológico" do corpo humano vulnerável é necessariamente a provocação de uma resposta, e, portanto, a provocação por uma resposta ética ${ }^{40}$.

Ela aborda extensamente o tema da ontologia no seu livro Quadros de guerra ${ }^{41}$, e tomo aqui algumas passagens do texto que ela intitula "Precarious life, grievable life"42, sua "Introdução" a esse livro. A referência feita na citação acima, de Ann V. Murphy, ao corpo humano vulnerável como um "fato ontológico" adquire pleno sentido na seguinte passagem de Butler:

Contudo, quero demonstrar que, se queremos ampliar as reivindicações sociais e políticas sobre os direitos à proteção e o exercício do direito à sobrevivência e à prosperidade, temos antes que nos apoiar em uma nova ontologia corporal que implique repensar a precariedade, a vulnerabilidade, a dor, a interdependência, a exposição, a subsistência corporal, o desejo, o trabalho e as reivindicações sobre a linguagem e o pertencimento social. Referir-se à 'ontologia' nesse aspecto

39 MURPHY, Ann V. Corporeal vulnerability and the new humanism. Hypatia, v. 26, n. 3, Summer. 2011. p. 575-590. Acompanharemos neste artigo a tradução de precariousness por "condição precária", adotada pela tradutora de Corpos em aliança para se referir a "uma condição universal de todo vivente, estar exposto à morte". (BUTLER, Judith. Corpos em aliança e a política das ruas: notas para uma teoria performativa da assembleia. 2. ed. Tradução: Fernanda Siqueira Miguens. Rio de Janeiro: Civilização Brasileira, 2018. p. 6.)

40 MURPHY, Ann V. Corporeal vulnerability and the new humanism. Hypatia, v. 26, n. 3, Summer. 2011. p. 577.

${ }^{41}$ BUTLER, Judith. Quadros de guerra: quando a vida é passível de luto? 5. ed. Tradução: Sérgio Lamarão e Arnaldo Marques da Cunha. Rio de Janeiro: Civilização Brasileira, 2018.

42 A tradução da edição brasileira para este título é "Vida precária, vida passível de luto". Conforme nosso comentário anterior, a expressão precarious life refere uma vida em condição precária, vulnerável e exposta à morte. Além disso, ela é frequentemente uma vida tomada como ungrievable, isto é, não merecedora de ser lamentada, pranteada, não merecedora de um trabalho de luto. 
não significa reivindicar uma descrição de estruturas do ser distintas de toda e qualquer organização social e política. Ao contrário, nenhum desses termos existe fora de sua organização e interpretação políticas. O 'ser' do corpo ao qual essa ontologia se refere é um ser que está sempre entregue a outros, a normas, a organizações sociais e políticas que se desenvolveram historicamente a fim de maximizar a precariedade para alguns e minimizar a precariedade para outros. Não é possível definir primeiro a ontologia do corpo e depois as significações sociais que o corpo assume. Antes, ser um corpo é estar exposto a uma modelagem e a uma forma social, e isso é o que faz da ontologia do corpo uma ontologia social ${ }^{43}$.

Evidencia-se assim que a ontologia em Butler é sempre uma ontologia que se realiza em um corpo vulnerável, em condição precária, e que é sempre um corpo imerso na linguagem e que toma existência em um espaço político e social. Por isso deve-se dizer, com ela, que toda ontologia do corpo é uma ontologia social. Ela critica a ideia de "pessoa" definida ontogeneticamente e sustentando "uma ontologia do individualismo que não reconhece que a vida, entendida como vida precária, implica uma ontologia social que coloca essa forma de individualismo em questão". Trata-se de uma ontologia que estabelece "a interdependência das pessoas, envolvendo relações sociais reproduzíveis e mantenedoras, assim como relações com o meio ambiente e com formas não humanas de vida, consideradas amplamente". Para esse modo de ontologia social "não existe nenhuma distinção absoluta entre o social e o ecológico"44.

Pretendo com estas breves referências ter apresentado algumas ideias iniciais para introduzir o leitor ao teor das reflexões de Butler a

\footnotetext{
43 BUTLER, Judith. Quadros de guerra: quando a vida é passível de luto? 5. ed. Tradução: Sérgio Lamarão e Arnaldo Marques da Cunha. Rio de Janeiro: Civilização Brasileira, 2018. pp. 15-16. 44 BUTLER, Judith, 2018, p. 38.
} 
respeito da ontologia, presentes ao longo de toda sua obra, enfatizando a integração dos elementos corporais, sociais e políticos nestas reflexões sobre este tema fundador da filosofia ${ }^{45}$.

\section{Ética e constituição do sujeito}

Como temos visto ao longo deste texto, a questão da constituição do sujeito e sua relação com a ética está presente desde as reflexões iniciais de Butler a partir de Hegel em sua tese de doutoramento ${ }^{46}$. O interesse de Butler pelo pensamento de Lévinas será crescente ao longo da sua produção textual. Na presente seção procurarei salientar a discussão de Butler com os testos de Lévinas em torno do tema da relação entre ética e constituição do sujeito.

Butler retoma o diálogo com Hegel em Relatar a si mesmo, em um capítulo que intitula "Questões pós-hegelianas". Toma a "Fenomenologia do Espírito", na seção intitulada "Independência e dependência da consciência-de-si: dominação e escravidão", para considerar que, em Hegel, o reconhecimento de uma consciência não pode ser dado de maneira unilateral: quando reconheço, sou potencialmente reconhecido, "e a forma em que ofereço o reconhecimento é potencialmente dada para mim". Sendo estruturalmente semelhantes, "a ação de uma implica a ação da outra. A consciência de si aprende essa lição primeiro no contexto da ação da agressão para com o outro, num esforço vão para destruir a similaridade

45 É oportuno lembrar aqui a interlocução de Butler com Derrida, presente em diversos momentos de sua obra. O pensamento político de Derrida é abordado por ela em texto publicado em 2009, como capítulo do livro Derrida and the time of the political. (BUTLER, Judith. Finishing, starting. In: $\mathrm{CHEAH}$, Pheng; GUERLAC, Suzanne. Derrida and the time of the political. Durham and London: Duke University Press, 2009. p. 291-306.) Em texto anterior examinei alguns aspectos da crítica de Derrida à ontologia constituída no seio do que ele nomeou "metafísica da presença" ocidental. (BOFF, Almerindo A. Freud, Lacan, Derrida: psicanálise em différance. Porto Alegre: Editora Fi, 2017. Disponível em: http://www.editorafi.org. Acesso em: 2 out. 2019). ${ }_{46}$ BUTLER, Judith. Subjects of desire: hegelian reflections in twentieth century France. New York: Columbia University Press, 1987. 
estrutural entre as duas e recolocar-se em situação soberana"47. Cita a seguinte passagem de Hegel:

182 - [Diese Bewegung] Mas esse movimento da consciência-de-si em relação a uma outra consciência-de-si se representa, desse modo, como o agir de uma (delas). Porém esse agir de uma tem o duplo sentido de ser tanto o seu agir como o agir da outra; pois a outra é também independente, encerrada em si mesma, nada há nela que não seja mediante ela mesma. A primeira consciência-de-si não tem diante de si o objeto, como inicialmente é só para o desejo; o que tem é um objeto independente, para si essente, sobre o qual nada pode fazer para si, se o objeto não fizer em si o mesmo que ela nele faz. O movimento é assim, pura e simplesmente, o duplo movimento das duas consciências-de-si. Cada uma vê a outra fazer o que ela faz; cada uma faz o que da outra exige - portanto faz somente o que faz enquanto a outra faz o mesmo. $\mathrm{O}$ agir unilateral seria inútil; pois, o que deve acontecer, só pode efetuar-se através de ambas as consciências. 183 - [Das Tun ist] Por conseguinte, o agir tem duplo sentido, não só enquanto é agir quer sobre si mesmo, quer sobre o Outro, mas também enquanto indivisamente é o agir tanto de um quanto de Outro ${ }^{48}$.

Para Butler, o outro hegeliano está sempre fora. Na sua leitura de Hegel, a relação com o outro é sempre extática, o que significa que

[...] o 'eu' se encontra repetidamente fora de si mesmo e que nada pode pôr fim no surto repetido dessa exterioridade que, paradoxalmente, é minha exterioridade. Sempre sou, por

\footnotetext{
47 BUTLER, Judith. Relatar a si mesmo: crítica da violência ética. Tradução: Rogério Bettoni. Belo Horizonte: Autêntica Editora, 2017. p. 39-40.

48 HEGEL, Georg W. F. Fenomenologia do Espírito. 4. ed. Tradução: Paulo Meneses. Petrópolis (RJ): Vozes: Bragança Paulista: Editora Universitária São Francisco, 2007. p. 143-144.
} 
assim dizer, outro para mim mesma, e não há um momento final em que aconteça meu retorno a mim mesma. ${ }^{49}$

Na sua leitura da "Fenomenologia do Espírito", o reconhecimento no encontro me torna

[...] outro diferente do que fui e assim deixo de ser capaz de retornar ao que eu era. Desse modo, há uma perda constitutiva no processo de reconhecimento, uma vez que o 'eu' é transformado pelo ato de reconhecimento. Nem todo seu passado é apreendido e conhecido no ato de reconhecimento; o ato altera a organização do passado e seu significado ao mesmo tempo que transforma o presente de quem é reconhecido. [...] O encontro com o outro realiza uma transformação do si-mesmo do qual não há retorno. No decorrer dessa troca reconhece-se que o si-mesmo é o tipo de ser para o qual a permanência dentro de si prova-se impossível. O si-mesmo é obrigado a comportar-se fora de si mesmo; descobre que a única maneira de se conhecer é pela mediação que acontece fora de si, exterior a si, em virtude de uma convenção ou norma que ele não criou, na qual não pode discernir-se como autor ou agente de sua própria construção..$^{\circ}$

Esta leitura de Hegel se mantém em harmonia com a noção freudiana da constituição do eu por ressignificação a posteriori (por um Nachträglichkeit, por um après-coup) no contexto de um trauma originário, noção compartilhada pela recepção lacaniana de Freud:

Lacan, como se sabe, deixou claro que qualquer que seja o relato que se dê sobre os momentos inaugurais do sujeito, ele sempre será tardio e fantasmático, afetado irreversivelmente

\footnotetext{
49 BUTLER, Judith. Relatar a si mesmo: crítica da violência ética. Tradução: Rogério Bettoni Belo Horizonte: Autêntica Editora, 2017. p. 41.

50 BUTLER, Judith. (2005) Relatar a si mesmo: crítica da violência ética. Tradução Rogério Bettoni. Belo Horizonte: Autêntica Editora, 2017. p. 41-2.
} 
por um Nachträglichkeit. Narrativas evolutivas tendem a errar ao supor que o narrador possa estar presente nas origens da história. A origem só se torna disponível retroativamente e através da tela da fantasia ${ }^{51}$.

Em seção seguinte do mesmo livro ela fará uma aproximação entre esta ideia e o pensamento de Lévinas por meio do desenvolvimento teórico de Jean Laplanche, na seção intitulada "Lapanche e Lévinas: a primazia do Outro". Birgit Schippers considera que o movimento de Butler, no sentido de tomar conceitos levinasianos no desenvolvimento do seu pensamento, toma impulso no seu esforço em procurar respostas para o problema da violência. Ela valorizará a ideia de Lévinas de uma radical alteridade na origem do sujeito, que só é possível porque existe um Outro anterior à sua emergência. No contexto de sua crítica a ideias de Lévinas examinada na seção anterior, é importante lembrar que, apesar de não acompanhá-lo em suas posições quanto ao sionismo ou quanto ao seu pensamento das obrigações éticas no contexto da tradição judaico-cristã, ela o acompanha no que se refere à relação entre ética e constituição do sujeito, como veremos a seguir ${ }^{52}$. Butler afirma que a sua análise política desenvolvida em "Corpos em aliança" considera que "uma reivindicação ética é, em algum sentido, anterior à formação do sujeito em questão, precedendo dessa forma as noções convencionais do contrato liberal"53 Ela entende que:

[...] para Lévinas, o sujeito é constituído pelo outro, e, embora algumas vezes o filósofo tenha em mente o outro 'infinito', ele também está certo de que essa infinidade só se faz conhecer

\footnotetext{
51 Idem. p. 73.

52 SCHIPPERS, Birgit. The political philosophy of Judith Butler. London and New York: Routledge, 2014. p. 89-90.

53 BUTLER, Judith. Corpos em aliança e a política das ruas: notas para uma teoria performativa da assembleia. 2. ed. Tradução: Fernanda Siqueira Miguens. Rio de Janeiro: Civilização Brasileira, 2018. p. 28.
} 
pelo rosto, o rosto de outra pessoa que carrega consigo uma exigência infinita. Pode-se dizer que a outra pessoa está 'ali', ela 'não sou eu', e, por isso, é uma 'alteridade' num sentido claramente localizável. Mas, ao mesmo tempo, [...] esse outro também me constitui, e, por dentro, eu sou cindida por essa exigência ética que, simultânea e indissoluvelmente, está 'ali' e 'aqui dentro' como condição constitutiva de mim mesma. [...] Na visão de Lévinas, há uma heterogeneidade que antecede meu ser e constantemente descentra o sujeito autônomo que pareço ser. Ela também complica permanentemente a questão da localização: onde 'eu' começo e termino, e quais são os parâmetros localizáveis do 'Outro'?54

Como vemos, Butler adota uma perspectiva teórica da origem do sujeito que coloca em harmonia concepções de Hegel, Freud, Lacan e Lévinas. Em todas elas, a interpelação ética está colocada no momento mesmo da origem do eu. Ela considera que, para Lévinas, "a não violência só surge como consequência de uma guerra interna ao si-mesmo contra seus próprios impulsos assassinos." Para ele, "[a] criatura humana é destituída, mas vale destacar que é com base nessa destituição que se elabora a obrigação de proteger a vida do outro". ${ }^{5}$

Embora esta obrigação venha posteriormente a ser codificada em sistemas éticos e legais, a sua origem, para Lévinas, é "an-árquica", isto é, sem princípio, como ela enfatiza com a seguinte citação do filósofo ${ }^{56}$ :

O nascimento do eu num remorso torturante, que é justamente um recolhimento para dentro de si mesmo [...]. A condição ou não-condição do si-mesmo não é uma afecção de si que pressupõe o Eu, mas precisamente uma afecção

54 BUTLER, Judith. Caminhos divergentes: judaicidade e crítica do sionismo. 5. ed. Tradução: Rogério Bettoni. São Paulo: Boitempo, 2017. p. 46-7.

55 Idem, p. 71-2.

${ }_{56} \quad$ Ibid., p. 72. 
pelo Outro, um traumatismo anárquico [an-árquico, sem princípio, e assim, seguramente, enigmático para o qual não se pode dar nenhuma causa clara], esse lado da afecção de si e da identificação de si, um traumatismo da responsabilidade e da não causalidade ${ }^{57}$.

Butler observa que esse "anarquismo" "é um afastamento do Logos e constitui outro 'fundamento' para pensarmos a relacionalidade humana como tal" 58 . Na citação de Lévinas acima, ele insere uma nota de rodapé em que a perseguição pela exigência ética constitui o ego original, concepção que se aproxima muito da teoria psicanalítica de Melanie Klein na qual o ego emerge em uma situação de angústia persecutória. Para Lévinas, o altruísmo é uma eleição não voluntária, inseparável dessa perseguição "an-árquica”:

Perseguição é um traumatismo, violência por excelência, sem aviso, sem a priori, sem a possibilidade de desculpa, sem logos. Perseguição leva de volta a uma resignação sem consentimento e como resultado atravessa uma noite do inconsciente. Este é o significado do inconsciente, a noite na qual o ego retorna a si mesmo no traumatismo da perseguição, uma passividade mais passiva ainda que toda passividade [...]"59.

Butler se refere à teoria de Melanie Klein da origem do ego e do amor em meio a sentimentos de ódio e perseguição na seguinte passagem:

Com bastante frequência, o que chamamos de 'amor' envolve sermos forçados por nossa própria opacidade, nossos

57 PEPERZAC, Adriaan T.; CRITCHLEY, Simon; BERNASCONI, Robert. Emmanuel Lévinas: basic philosophical writings. Bloomington and Indianapolis: Indiana University Press, 1996. p. 93-4. (tradução nossa)

${ }_{58}$ BUTLER, Judith. Caminhos divergentes: judaicidade e crítica do sionismo. 5. ed. Tradução: Rogério Bettoni. São Paulo: Boitempo, 2017. p. 72.

59 PEPERZAC, Adriaan T.; CRITCHLEY, Simon; BERNASCONI, Robert. Emmanuel Lévinas: basic philosophical writings. Bloomington and Indianapolis: Indiana University Press, 1996. p. 183. 
próprios lugares de desconhecimento e, com efeito, nossa própria injúria (é por isso que, por exemplo, Melanie Klein insiste que as fantasias de reparação estruturam o amor $)^{60}$.

Ilustramos, desta maneira, a afinidade da concepção de Butler, a respeito da ligação intrínseca entre a constituição do sujeito e sua dimensão ética, com os desenvolvimentos teóricos da psicanálise e das filosofias de Hegel e Lévinas.

\section{Pluralidade, performatividade, multiculturalismo e ativismo social}

No percurso do seu pensamento, Butler ampliou progressivamente a sua crítica da dominação patriarcal masculina sobre a expressão da sexualidade para uma crítica da dominação do capitalismo tardio neoliberal e de sua violência. Sua elaboração teórica parte da crítica inicial da restrição teórica ao marco referencial da filosofia fenomenológica na década de oitenta, como veremos adiante, para uma defesa do valor da pluralidade do pensamento, como ela expressa em entrevista recente:

Para mim a tarefa não é encontrar um referencial único ou sintético, mas encontrar uma maneira de pensar em aliança. A aliança é grande e está em expansão, e é uma luta por uma democracia mais radical. Se há um projeto político comum é na afirmação de uma sociedade que irá se associar para combater as novas formas de autoritarismo e de fascismo. ${ }^{61}$

O tema da pluralidade é discutido por ela no contexto dos pensamentos de Emmanuel Lévinas e Hanna Arendt. Segundo Arendt, Eichmann não

\footnotetext{
60 BUTLER, Judith. Relatar a si mesmo: crítica da violência ética. Tradução Rogério Bettoni. Belo Horizonte: Autêntica Editora, 2017. p. 133.

${ }_{61}$ BUTLER, Judith. Une façon de penser en alliance. [Entrevista cedida a Pierre Chaillan, publicada em l'Humanité em 8 mar. 2018 Disponível em: https://www.humanite.fr/judith-butler-une-facon-de-penser-en-alliance-651696. Acesso em: 22 jun. 2019.
} 
entendia que ninguém goza da prerrogativa de escolher com quem vive na Terra. Se pudéssemos decidir com quem conviver na Terra, estaríamos decidindo qual porção da humanidade pode viver e qual deve morrer:

Para Arendt, o caráter compulsório da convivência na terra é a condição da nossa própria existência como seres éticos e políticos. Por isso, exercer a prerrogativa do genocídio é destruir não apenas as condições políticas da individualidade, mas também a própria liberdade, entendida não como um ato individual, e sim como uma ação plural. Sem essa puralidade, que não podemos escolher, não temos liberdade e, portanto, não temos escolha. Isso significa que existe uma condição compulsória da liberdade e que, ao sermos livres, afirmamos algo sobre aquilo que não podemos escolher. (...) [na visão de Arendt] devemos conceber instituições e políticas que preservem e afirmem, de maneira ativa, o caráter compulsório de uma convivência plural e ilimitada. Não apenas vivemos com aqueles que não escolhemos e em relação aos quais podemos não sentir uma sensação imediata de pertencimento social, mas também somos obrigados a preservar essas vidas e a pluralidade ilimitada que constitui a população global ${ }^{62}$.

Butler considera possível partir da ideia de Arendt de que "a política depende de uma ação em conjunto" para repensar a forma como o corpo pode se tornar parte da ação e objetivo da política, levando a "uma noção de pluralidade pensada juntamente com a performatividade e a interdependência"63.

Esta possibilidade de participação performativa do corpo na política só existe quando há liberdade de aparecimento incondicional de qualquer pessoa no espaço público:

\footnotetext{
62 BUTLER, Judith. Corpos em aliança e a política das ruas: notas para uma teoria performativa da assembleia. 2. ed. Tradução: Fernanda Siqueira Miguens. Rio de Janeiro: Civilização Brasileira, 2018. p. 123-125.

63 Idem, p. 165.
} 
Em termos arendtianos, podemos dizer que ser excluído do espaço de aparecimento, ser impedido de ser parte da pluralidade que constitui o espaço de aparecimento, é ser privado do direito de ter direitos. A ação plural e pública é o exercício do direito de se ter um lugar e pertencer, e esse exercício é o meio pelo qual o espaço de aparecimento é pressuposto e constituído. ${ }^{64}$

Embora a ideia de performatividade seja frequentemente associada a atos individuais e à performatividade linguística, neste texto ela é estendida por Butler para descrever formas de performatividade corpórea coletiva apresentada pela reunião dos corpos em "assembleia" no espaço público, a exemplo do ocorrido no movimento Ocuppy ou na "Primavera Árabe":

Assembleias populares se formam inesperadamente e se dissolvem sob condições voluntárias ou involuntárias, e essa transitoriedade está, eu gostaria de sugerir, relacionada à sua função 'crítica'. [...] importa que os corpos se reúnam em assembleia e que os significados políticos transmitidos pelas manifestações sejam não apenas aqueles transmitidos pelo discurso, seja ele escrito ou falado. Ações corporificadas de diversos tipos significam, de forma que não são, estritamente falando, nem discursivas nem pré-discursivas. Em outras palavras, formas de assembleia já têm significado antes e apesar de qualquer reivindicação particular que façam ${ }^{65}$.

Este é o momento oportuno para salientarmos a importante deriva que o conceito de performatividade realiza desde os momentos iniciais da obra de Butler, onde ele é teorizado em relação ao conceito de performatividade do gênero, até a ampliação do seu alcance no campo da filosofia política. Lembramos que este movimento do seu pensamento está de acordo com a sua concepção da prática filosófica:

\footnotetext{
64 lbid., p. 66.

65 Ibid., p. 13-14.
} 
Em nossa prática da filosofia no mundo contemporâneo, estamos continuamente registrando o mundo histórico e suas demandas dentro dos termos do nosso pensamento. Como podemos responder a elas - demandas por compreender e por criticar - sem reproduzir as categorias históricas que constituem o problema? E além disso, como fazer isso sem agir como se pudéssemos escapar da história? ${ }^{36}$

Quando, em 1988, aborda o tema no artigo "Performative acts and gender constitution: an essay in phenomenology and feminist theory"67, ela observa inicialmente que os filósofos, apesar de raramente se referirem ao atuar no sentido da atuação teatral, apresentam um discurso sobre os "atos" que mantêm significados semânticos associativos com teorias da performance e do atuar. Toma, no início, exemplos em John Searle e nas fenomenologias de Husserl e Merleau-Ponty, para a seguir passar a cotejar as visões feminista e fenomenológica por meio de Simone de Beauvoir. Discute a utilidade de tomar um ponto de partida fenomenológico para uma descrição feminista do gênero, afirmando que a apropriação feminista da teoria fenomenológica da constituição do gênero deve empregar a noção de "ato" em um sentido ricamente ambíguo, revisando as posições teóricas individualistas subjacentes à visão mais restrita dos atos constitutivos dentro do discurso fenomenológico. Conclui que o gênero é um ato performativo, amplamente construído, que constrói a ficção social de sua própria interioridade psicológica. Portanto, não é determinado pela natureza, pela linguagem, pelo simbólico, nem é passivamente roteirizado no corpo. Como um campo corporal de jogo cultural, o gênero constitui

\footnotetext{
66 DORSAL JOURNAL. Philosophy or activism? Interview with Judith Butler. Dorsal, n. 1, p. 111-117, jun. 2018,. Disponível em: http:// www.revistas.cenaltes.cl/index.php/dorsal Acesso em: 21 jun. 2019. p. 112. (tradução nossa).

${ }_{67}$ BUTLER, Judith. Performative acts and gender constitution: an essay in phenomenology and feminist theory. Theatre Journal. The Johns Hopkins University Press, v. 40, n. 4, p. 519531, dez., 1988.
} 
uma oportunidade inovadora para expandir o campo cultural por meio de performances subversivas de vários tipos.

Saliento aqui a presença, neste texto de 1988, dos temas fundamentais que serão discutidos em sua obra com progressiva ampliação para uso no campo da filosofia política. O tema da constituição do sujeito por um jogo interativo com o Outro, com a linguagem e com a cultura, bem como a possibilidade do uso performativo do corpo como agente potencialmente transformador da sociedade, está presente nesse texto inicial em discussão com as suposições subjacentes à filosofia fenomenológica e como crítica às teorias vigentes na época sobre o processo de constituição do gênero.

Cotejamos aqui este momento inicial da sua trajetória com o alcance ampliado que apresentam em seu livro publicado em $2015^{68}$. O livro discute os caminhos necessários e possíveis para que um grande número de corpos individuais constituam uma "assembleia" de "corpos em aliança" que agirão performativamente no espaço público colocando em ação uma "política das ruas" na qual "corpos incontáveis" produzem uma "performatividade incalculável"69.

Cabe aqui uma pequena digressão a respeito dessas duas últimas expressões. A expressão "corpos incontáveis" remete ao trabalho teórico de Butler sobre os "corpos que não contam", ou seja, corpos que não merecem ser pranteados, corpos cuja morte não é considerada digna de ser lamentada, pranteada, cuja morte não é merecedora de luto pela perda de uma vida: trata-se de vidas que "não contam"7o. Exemplo disso é a morte de civis palestinos em Gaza: mortes que não são "contadas", no sentido

68 BUTLER, Judith. Corpos em aliança e a política das ruas: notas para uma teoria performativa da assembleia. 2. ed. Tradução: Fernanda Siqueira Miguens. Rio de Janeiro: Civilização Brasileira, 2018.

69 As expressões "corpos incontáveis" e "performatividade incalculável" são aqui introduzidas por este autor a partir do título da entrevista de Butler concedida a Athena Athanasiou: "Uncounted bodies, incalculable preformativity" (Publicada em BUTLER, Judith; ATHANASIOU, Athena. Dispossession: the performative in the political. Cambridge (UK): Polity Press, 2013. p. 97-103.) 70 BUTLER, Judith. Quadros de guerra: quando a vida é passível de luto? 5. ed. Tradução: Sérgio Lamarão e Arnaldo Marques da Cunha. Rio de Janeiro: Civilização Brasileira, 2018. 
de que não aparecem nos cálculos das estatísticas da guerra divulgadas pela grande imprensa71. E também não são "contadas" no sentido de que não são narradas, permanecendo ocultadas pelo silêncio. A expressão "performatividade incalculável" pode ser tomada também para sugerir que os efeitos da performatividade da "assembleia" no espaço público não são passíveis de mensuração ou cálculo, o que nos remete também às reflexões de Derrida, interlocutor de Butler em alguns textos, sobre o tema da incalculabilidade, daquilo que não "conta", que não se sujeita ao cálculo.72

Outro aspecto que Butler enfatiza em texto recente é que o conceito de performatividade abrange tanto o sentido passivo do termo (por exemplo, o ato de ser objeto passivo e acrítico de uma dada performance no espaço social) quanto as condições e possibilidades para agir, não podendo ser compreendida a sua operação sem levar em conta ambas dimensões. ${ }^{73}$ Devido a esta dimensionalidade dual da performatividade, nós estamos invariavelmente sendo "atuados" passivamente e atuando ativamente, e esta é uma das razões pelas quais a performatividade não pode ser reduzida à ideia de uma performance livre individual74.

Um último aspecto que recordamos aqui quanto às posições de Butler no campo da filosofia política é seu posicionamento teórico a favor da política de coligação em detrimento do multiculturalismo. Aquela permitiria a possibilidade de coalescimento em torno de objetivos compartilhados sem presumir, como ocorre no multiculturalismo, uma identidade compartilhada. Em Quadros de guerra ela considera que "os discursos normativos

\footnotetext{
71 BUTLER, Judith; ATHANASIOU, Athena. Dispossession: the performative in the political. Cambridge (UK): Polity Press, 2013. p. 100.

72 Além do diálogo já referido de Butler com Derrida (ver nota 45 acima), uma discussão do tema da posição de Derrida em relação à globalização e seus efeitos se encontra em EVANS, Fred. Cosmopolitanism to come: Derrida's response to globalization. In: DIREK, Zeynep; LAWLOR, Leonard (eds.) A companion to Derrida. Oxford: Wiley Blackwell, 2014.

73 BUTLER, Judith. Rethinking vulnerability and resistance. In: BUTLER, Judith; GAMBETTI, Zeynep; SABSAY, Leticia (eds.) Vulnerability in resistance. Durham and London: Duke University Press, 2016. p. 18.

74 Idem, p. 24.
} 
derivados do liberalismo e do multiculturalismo são inadequados para a tarefa de compreender tanto as novas formações do sujeito quanto as novas formas de antagonismo social e político". ${ }^{75}$ Ela observa:

Parte do problema da vida política contemporânea é que nem todo mundo conta como sujeito. O multiculturalismo tende a pressupor comunidades já constituídas, sujeitos já estabelecidos, quando o que está em jogo são comunidades não exatamente reconhecidas como tais, sujeitos que estão vivos, mas que ainda não são considerados 'vidas'”. ${ }^{76}$ [...] Os sujeitos subentendidos pelos enquadramentos liberais e multiculturais (e vamos ter que tentar fazer uma distinção entre eles) caracterizam-se por pertencer a certos tipos de identidades culturais, concebidos de formas variadas como individual ou multiplamente determinados por uma série de categorias que incluem etnicidade, classe, raça, religião, sexualidade e gênero".77 [...] O multiculturalismo que requer certo tipo de sujeito, na verdade institui essa exigência conceitual como parte integrante de sua descrição e de seu diagnóstico. Que formações de subjetividade, que configurações de mundos de vida são apagadas ou obstruídas por tal movimento obrigatório? ${ }^{78}$

A menção a configurações de vidas apagadas do discurso remete também ao fato de que este apagamento opera uma distinção entre existências humanas merecedoras de existência e não merecedoras de existência:

Se certas vidas são consideradas merecedoras de existência, de proteção e passíveis de luto e outras não, então essa maneira de diferenciar as vidas não pode ser entendida como um problema de identidade nem sequer de sujeito. Trata-se,

\footnotetext{
75 BUTLER, Judith. Quadros de guerra: quando a vida é passível de luto? 5. ed. Tradução: Sérgio Lamarão e Arnaldo Marques da Cunha. Rio de Janeiro: Civilização Brasileira, 2018. p. 209.

76 Ibid, p. 54.

77 lbid., p. 198.

78 Ibid., p. 229
} 
antes, de uma questão de como o poder configura o campo em que os sujeitos se tornam possíveis ou, na verdade, como eles se tornam possíveis. E isso implica uma prática crítica de pensamento que se recusa a aceitar sem discutir o enquadramento da luta identitária que pressupõe que os sujeitos já existem, que ocupam um espaço público comum e que suas diferenças podem ser reconciliadas se tivermos ferramentas adequadas para uni-los. ${ }^{79}$

Essas reflexões de Butler se aplicam tanto à política de coligação conduzida no plano global quanto às condições de heterogeneidade no campo da política doméstica. Ela defende a ideia de que a política de coligação articula condições de diversidade, pluralidade e heterogeneidade sem recorrer a políticas identitárias, já que ela opera sob condições de antagonismo e coalesce em torno da crítica do poder e da violência do Estado. Nesse cenário, a mobilização de alianças não se dá necessariamente entre sujeitos estabelecidos e reconhecíveis e não depende da acordos quanto a demandas identitárias. Nestas condições, o sujeito da política de coligação, na visão de Butler, se torna "um conjunto ativo e transitivo de interrelações"

Pretendemos nestes breves parágrafos ter ilustrado a forma como o alcance das reflexões de Butler se amplia desde o seu momento inicial, enfocado na questão da performatividade do gênero para a ênfase nas implicações do conceito de performatividade para a filosofia política e o ativismo social contemporâneos.

\section{Considerações finais}

A apresentação de um artigo que pretende reunir notas introdutórias ao pensamento de uma filósofa implica prévia renúncia ao aprofundamento

\footnotetext{
79 Ibid., p. 231-232.

80 SCHIPPERS, Birgit. The political philosophy of Judith Butler. London: Routledge, 2014. p. 98.
} 
da discussão dos temas mencionados. Ao pagar este preço, nos sentimos recompensados com a possibilidade de despertar no leitor curiosidade e oferecer-lhe elementos iniciais para que siga a investigar com maior profundidade os temas aqui esboçados à guisa de estímulo ao interesse pelo estudo da filosofia política de Judith Butler.

\section{Referências}

BOFF, Almerindo A. Freud, Lacan, Derrida: psicanálise em différance. Porto Alegre: Editora Fi, 2017. Disponível em: http://www.editorafi.org. Acesso em: 02 maio 2019.

BUTLER, Judith. Subjects of desire: hegelian reflections in twentieth century France. New York: Columbia University Press, 1987. https://doi. org/10.5040/9781472545688.ch-001

BUTLER, Judith. Performative acts and gender constitution: an essay in phenomenology and feminist theory. Theatre Journal, Baltimore, v. 40, n. 4, p. 519-531, Dec. 1988. https://doi.org/10.2307/3207893

BUTLER, Judith. Problemas de gênero: feminismo e subversão da identidade. 17. ed. Tradução Renato Aguiar. Rio de Janeiro: Civilização Brasileira, 2019. BUTLER, Judith. (1990). https://doi.org/10.30715/rbpe.v19.n1.2017.10819

BUTLER, Judith. Bodies that matter: on the discursive limits of "sex". London: New York: Routledge, 1993.

BUTLER, Judith. Excitable speech: a politics of the performative. London: New York: Routledge, 1997.

BUTLER, Judith. Undoing gender. London: New York: Routledge, 2004. https:// doi.org/10.4324/9780203499627

BUTLER, Judith. Relatar a si mesmo: crítica da violência ética. Tradução Rogério Bettoni. Belo Horizonte: Autêntica Editora, 2017. BUTLER, Judith. (2005).

BUTLER, Judith. Quadros de guerra: quando a vida é passível de luto?. 5. ed. Tradução Sérgio Lamarão e Arnaldo Marques da Cunha. Rio de Janeiro: Civilização Brasileira, 2018. BUTLER, Judith. (2009).

BUTLER, Judith. Finishing, starting. In: CHEAH, Pheng; GUERLAC, Suzanne. Derrida and the time of the political. Durham: London: Duke University Press, 2009. p. 291-306. https://doi.org/10.1215/9780822390091-015 
BUTLER, Judith. Caminhos divergentes: judaicidade e crítica do sionismo. 5. ed. Tradução Rogério Bettoni. São Paulo: Boitempo, 2017. BUTLER, Judith. 2012. BUTLER, Judith. Corpos em aliança e a política das ruas: notas para uma teoria performativa da assembleia. 2. ${ }^{a}$ ed. Tradução Fernanda Siqueira Miguens. Rio de Janeiro: Civilização Brasileira, 2018. BUTLER, Judith. (2015). https://doi. org/10.30612/nty.v7i10.10315

BUTLER, Judith. Senses of the subject. New York: Fordham University Press, 2015 .

BUTLER, Judith. Levantes. In: DIDI-HUBERMAN, Georges (org.). Levantes. Tradução Jorge Bastos, Edgard de Assis Carvalho, Mariza Perassi Bosco e Eric R. R. Heneault. São Paulo: Edições SESC São Paulo, 2017. BUTLER, Judith, (2016). https://doi.org/10.11606/issn.2178-0447.ars.2016.123427

BUTLER, Judith. Reply from Judith Butler. Philosophy and Phenomenological Research, Buffalo, NY, v. XCVI, n.1, p. 243-249, Jan. 2018. Book Symposium. https://doi.org/10.1111/phpr.12481

BUTLER, Judith; ATHANASIOU, Athena. Dispossession: the performative in the political. Cambridge: Polity Press, 2013. https://doi.org/10.25158/16.1.21 BUTLER, Judith; GAMBETTI, Zeynep; SABSAY, Leticia (ed.). Vulnerability in resistance. Durham: London: Duke University Press, 2016. https://doi. org/10.1163/15692086-12341320

BUTLER, Judith; LACLAU, Ernesto; ZIZEK, Slavoy. Contingency, hegemony, universality: contemporary dialogues on the left. London: New York: Verso, 2000. BUTLER, Judith; MALABOU, Catherine. Sois mon corps: une lecture contemporaine de la domination et de la servitude chez Hegel. Montrouge (FR): Bayard Éditions, 2010.

CHOMSKY, Noam; PAPPÉ, Ilan. On Palestine. Chicago: Haymarket Books, 2015. DORSAL JOURNAL. Philosophy or activism? Interview with Judith Butler. Dorsal. Revista de Estudios Foucaultianos, [S. l.], n.1, p. 111-117, jun, 2018. Disponível em: http:// www.revistas.cenaltes.cl/index.php/dorsal. Acesso em: 21 jun. 2019. EVANS, Fred. Cosmopolitanism to come: Derrida's response to globalization. In: DIREK, Zeynep; LAWLOR, Leonard (ed.). A companion to Derrida. Oxford: Wiley Blackwell, 2014. https://doi.org/10.1002/9781118607138.ch33

GIULIANI, Facundo (org.). Rebeliones éticas, palabras comunes: conversaciones (filosóficas, políticas, educativas) com Judith Butler, Raúl Fornet-Betancourt, 
Walter Mignolo, Jacques Rancière e Slavoy Zizek. Buenos Aires: Mino y Dávila Editores, 2017.

HAND, Seán. (ed.). The Levinas reader. Oxford: Blackwell Publishing, 1989.

HEGEL, Georg W. F. Fenomenologia do Espírito. 4. ed. Tradução Paulo Meneses. Petrópolis (RJ): Vozes; Bragança Paulista: Editora Universitária São Francisco, 2007.

JORONEN, Mikko. Negotiating colonial violence: spaces of precarisation in Palestine. Antipode, [S. l.], v. 51, n. 3, p. 838-857, 2019. https://doi.org/10.1111/ anti.12518

LÉVINAS, Emmanuel. Difficult freedom: essays on judaism. Baltimore: The Johns Hopkins University Press, 1997.

MURPHY, Ann V. Corporeal vulnerability and the new humanism. Hypatia, [S. l.], v. 26, n. 3, Summer 2011. https://doi.org/10.1111/j.1527-2001.2011.01202.x PAPPÉ, Ilan. The ethnic cleansing of Palestine. London: Oneworld Publications, 2006.

PEPERZAC, Adriaan T.; CRITCHLEY, Simon; BERNASCONI, Robert. Emmanuel Lévinas: basic philosophical writings. Bloomington and Indianapolis: Indiana University Press, 1996.

SCHIPPERS, Birgit. The political philosophy of Judith Butler. London: New York: Routledge, 2014. https://doi.org/10.4324/9780203551530

\section{Endereços postal}

Rua Dr. Florêncio Ygartua, 391/404

Bairro Rio Branco

Porto Alegre - RS

CEP 90.430-010 